\title{
Complexity and Memory: Financial Related Issues Among HBCUs
}

\author{
Kenneth L. Shropshire \\ University of Pennsylvania
}

The purpose of this paper is to offer a response to Johnson's (2013) comments. The author offers a defense of the important role Historically Black Colleges and Universities have historically played and continue to do so today.

The purpose of this paper is to respond to the remarks made by Dr. Johnson (2013). I appreciate the opportunity to do so, as often lost in the multiple conversations about collegiate athletics is the role of historically black colleges and universities (HBCUs). As I read and now listened to Dr. Johnson's remarks, I thought, what more can I add? So in my brief time I hope to provide a bit more of a frame as we move forward in the 21st century when the question that will periodically emerge will not only be the role of HBCUs and athletics but the role of HBCUs. This terminal question is an inescapable part of this important conversation.

If you know me or have looked at my work, you know how important I think it is for any scholar seeking to be critical to fully disclose their background. This is at the heart of critical race studies led by the late Professor Derrick Bell. My disclosure is this: Although I have this traditional pedigree highlighted with Stanford, Columbia, and Penn, I am a product of HBCUs. I am a proud product of HBCUs. My mother grew up at and attended Langston University in Langston, Oklahoma, where my grandfather taught Chemistry. Before that he taught at Philander Smith, another HBCU in Little Rock, Arkansas. My maternal grandmother attended Wilberforce College in Wilberforce, Ohio. My father returned from World War II and attended Johnson C. Smith in Charlotte, North Carolina. My parents met at Meharry Medical College in Nashville, Tennessee. So you see I am a product of HBCUs.

Old Jim Crow allowed the generation before me and further back no other options. HBCUs were their pathway to education. With that critical revelation made, I simply want to highlight two themes to provide appropriate support to HBCUs as outlined by Dr. Johnson. Complexity and Memory

Shropshire is the David W. Hauck Professor at the Wharton School of the University of Pennsylvania and the Director of its Wharton Sports Business Initiative, Philadelphia, PA. 


\section{Complexity}

In 1978, I was a student at Columbia and took a small civil rights seminar-about 8 students-with one of the pillars of Brown v. Board of Education and close colleague of Justice Thurgood Marshall, Jack Greenberg. ${ }^{1}$ About the third week of the class, Greenberg walked in looking troubled and he opened with a question that I paraphrase: "Should we [the NAACP Legal Defense Fund, Inc.] bring an action against HBCUs so that they proactively increase the number of white students enrolled?"

What followed was a memorable heated contentious discussion at the role of HBCUs. The class focused on the historic role and then the debated question, what is the role today? The conversation propelled me to move from my historic understanding to thinking about the practical role of HBCUs in 1978. I mean, we had come so far! I am sure at the time that I did not recognize that this was a pedagogical ploy on the part of a great lawyer, thinker, and professor.

That conversation leads us to what role HBCUs have and should have in the 21 st century? Understanding this current role as well as working to define and implement even greater future societal value provides the rationale to support the principles exposed by Dr. Johnson. This is where we must pause to and recognize that these institutions Dr. Johnson examined are not monolithic. All do not soften the financial problems of Barber-Scotia and Morris Brown Colleges. ${ }^{2}$ Those are, however, the HBCUs that often dominate the headlines.

The 21st Century understanding we must come to is that these schools have gone from the exclusive pathway for the higher education of African Americans, as was the case for my family, to the lone pathway for many families. In the domain of schools, there is one that fits virtually anyone, but there is also a unique underutilized grant that can strategically be used to address "The New Jim Crow" issues raised by author Michelle Alexander. ${ }^{3}$ Not to belabor, but she is the leading researcher pointing to the warehousing of young Black men not just in prison but in the wallless prison of the judicial system. She maintains that as more African-Americans have systematically been incarcerated, they have subsequently been deprived of rights ranging from the right to vote, housing, employment and basic human rights. A deprivation arguably much more severe than simply legally separating the races under the old Jim Crow confronted by my forbearers. Can we merge the support of HBCUs with the mission of providing a pathway away from the New Jim Crow system? For this reason alone HBCU's have a 21 st century role that cries out for our efforts of support.

The bigger issue is-unlike the financial and insurance industry debates on whether we should or should not let that enterprise fail or whether AIG is too big to fail-that HBCUs are way too important to fail, no matter how complex supporting these entities may be.

\section{Memory}

I was at a sports conference in Qatar. ${ }^{4}$ I received a notice upon checking into the conference hotel that Oscar Pistorius, the South African sprinter, was going to race a horse (this was before the murder accusations that he is facing at the time of 
this writing). My memory immediately took me to Jesse Owens tragically racing horses upon his homecoming from the 1936 Berlin Olympics. I made it a point of asking attendees if they were as uncomfortable with the idea as me. I even posted the event on Facebook. Some expressed outrage. Many more simply commented on the novelty or queried who had won.

Sport and HBCUs have many important memory elements. I contend that the dominant athletic institutions of the NCAA today are to HBCUs, as Major League Baseball is to the Negro Leagues. The success of the former is built on the decline of the latter. Memory takes us to years when Grambling sent as many players to the pros as Notre Dame in a given year. As conference realignments occur and these schools benefit, HBCUs continue to be, as Derrick Bell framed for us, the Faces at the Bottom of the Well.

Jack Greenberg was right to ask that question back in 1978. The probing in that scholarly setting, as is this case in this one, is to recollect the powerful role of these institutions: that complexity; the memory. But also, for us, to support the necessary role of HBCUs in the 21st Century. A purposeful role intertwined with addressing the New Jim Crow that is impacting us all.

Thank you again Dr. Johnson for outlining what is being done. The important conversation for us is what more can we do?

\section{Notes}

1. http://www.law.columbia.edu/fac/Jack_Greenberg

2. http://www.thecharlottepost.com/index.php?src=news\&srctype=detail\&category=News\&r efno $=1766$

3. http://yaledailynews.com/blog/2013/02/26/civil-rights-lawyer-explains-the-new-jim-crow/

4. http://www.dohagoals.com/en/goal/about

\section{References}

Johnson, M. (2013). Financial and related issues among Historically Black Colleges and Universities. Journal of Intercollegiate Sport, 6, 65-75. 